\title{
Effects of the COVID-19 pandemic on post graduate gynecological training and surgical skills: Indian perspective
}

\author{
Avir Sarkar, MD, Pradip Kumar Saha, MD, Rashmi Bagga, MD \\ Department of Obstetrics and Gynecology, Postgraduate Institute of Medical Education and Research, Chandigarh, India
}

After a cluster of cases of pneumonia was reported in the Wuhan province of China in December 2019, a new strain of Coronavirus gained global importance. It rapidly spread across various countries. Deeply concerned by its alarming levels of spread and severity, the WHO finally called it a pandemic [1]. The year to come would be dominated by this single event, as no year has been since the Second World War. Going through the euphoria of false victory due to herd immunity by the beginning of 2021, India stepped into the critical stage after the emergence of new strains [2]. With more than 20.2 million cases of COVID-19 being reported, a rolling average of 4,12,262 cases daily and death tolls crossing 3,980 per day, hospitals, and health workers were overwhelmed and exhausted across the country $[1,2]$. As a result, a draconian step needs to be taken. The economic fallout after the pandemic threatens a wave of defaults across the globe, where people are foreseeing the darkened sky of the gloomy evening with a picture of millions being pushed into extreme poverty and famine amidst acute scarcities. With the virus spreading to 220 countries extensively, the human toll in India after the second wave is more than double the number of humans killed over 320 natural disasters during the past two decades [1]. The COVID-19 pandemic has created the largest disruption in social, economic, political, and educational systems in history.

We have now realized that medical fraternities need more workforces to embrace the enduring competencies of professionalism, thereby accounting for better skills for addressing the health challenges today [3]. Successful residency in medical careers have always implied perseverance in both theory and practical classes. One has to give extra conference presentations, do well in bedside clinics, and have meaningful non-academic extra-curricular activities as well. A combined effort of all these aspects reflects the knowledge, persistence, dedication, and collaborative spirit of a medical scholar. This trajectory has suffered a detrimental disruption owing to the suspension of curriculum in recent times. Reduction in patient interaction, which is vital for both skill acquisition and relationship building, has become a serious issue that needs urgent attention. Students are thereby losing the opportunity for personal development through case presentations and bedside examinations.

Looking into the Indian scenario, the second wave of COVID-19 affected the country the most. Hospitals across the country experienced a dwindling oxygen supply and a scarcity of beds [4]. In such heartbreaking times prevalent in India, lack of manpower has compelled the government to take strict decisions regarding deployment of final year MBBS students and intern doctors to COVID-19 dedicated duties across the nation [4]. As hospitals have exploded with the growing number of COVID-19 patients across countries, most medical associations have already formulated guide-

Received: 2021.06.21. Revised: 2021.07.14. Accepted: 2021.07.15. Corresponding author: Pradip Kumar Saha, MD

Department of Obstetrics and Gynecology, Post Graduate Institute of Medical Education and Research (PGIMER), Sector 12,

Chandigarh, Pin 160012, India

E-mail: pradiplekha@yahoo.co.in

https://orcid.org/0000-0002-3200-4124

Articles published in Obstet Gynecol Sci are open-access, distributed under the terms of the Creative Commons Attribution Non-Commercial License (http://creativecommons. org/licenses/by-nc/3.0/) which permits unrestricted non-commercial use, distribution, and reproduction in any medium, provided the original work is properly cited.

Copyright $\odot 2021$ Korean Society of Obstetrics and Gynecology 


\title{
Obstetrics \& Gynecology Science
}

\author{
Vol. 64, No. 5, 2021
}

lines to curtail elective surgeries and non-urgent oncosurgeries to optimize labor, hospital beds, and oxygen facilities for COVID-19 patients. Thus, most specialty clinics and hospital wards have been transformed into COVID-19 dedicated wards. Medical colleges have shifted their clinical and practical classes to an online format. During the first spike in 2020, medical classes were conducted via a hybrid format with theory classes being online and bedside clinics conducted through offline short batches. However, the dreadful second spike this year has compelled the government to suspend all offline classes. While online classes can be an alternative for undergraduate students, postgraduate $(\mathrm{PG})$ medical careers are suffering the most. Poorer is the situation with surgical branches, such as gynecology, where bedside examination skills and repeated exposure to a variety of operative cases play a vital role in building up a perfect surgeon. Now, the PG students are expected to attend COVID-19 postings as a moral obligation and need of the country in this difficult situation. Due to the ongoing circumstances, non-COVID-19 admissions have already been curtailed, leaving a limited option for PG scholars.

Owing to the highly contagious nature of the virus, it has become difficult to continue routine classes and lectures, thereby affecting medical education, which is predominantly based on patient-oriented bedside classes. Routine gynecology out patient departments and infertility clinics have already been suspended long back [5]. Elective surgeries have suffered a devastating setback amidst the rapid outburst of COVID-19 cases [5]. Suspension of clinical rotatory postings, elimination of bedside classes, changes in medical examinations, and alterations in grading systems have further crippled the medical curriculum [6]. With the surge of the infectious COVID-19, infertility practice has suffered setbacks, and scholars pursuing fellowship courses in infertility are getting their degrees without getting much experience to perform ovum-pickups, embryo transfers, or other advanced assisted reproductive techniques [5]. Similar is the situation with fellowship courses in urogynecology and laparoscopy courses. Being a one-year curriculum, scholars pursuing these courses started during the initial outburst of the pandemic and are getting their degrees without even practicing in their field of study. This can prove detrimental to their long-term surgical careers.

Reduction in the number of non-COVID-19 admissions in hospitals across the country is making it very difficult for
PG scholars to recruit subjects for their proposed theses. As a result, repeated attempts are being made to dwindle the sample size of their studies, thereby reducing the strength of their study. Gone are the days when morning and evening bedside rounds with senior and junior consultants would increase skill in detailed history taking and clinical examinations. It is becoming a great debate as to how much justice we are doing to our subject when students are expected to perform COVID-19 duties and learn no/minimal surgical and technical skills and procedures that are traditionally used to form the core topics of our subject.

It is time for expert committees of medical education to ponder this aspect. Some of the most commonly proposed methods to address this are as follows:

1. Conducting frequent live online interactive video lectures or pre-recorded self-study classes will definitely benefit the youth during this time of crisis.

2. Virtual clinical experience has also been proposed. By interacting and interviewing patients' attendants, helping in paperwork and counseling about the course of the illness and their prognosis, medical students will learn to play the role of healthcare professionals.

3. There may be provisions for extending the course curriculum of PG students for a brief period of six months or so, after the peak of the deadly pandemic flattens. This will definitely give them an extra edge to get a firm grip on their subject once non-COVID-19 routine admissions resume.

4. Thesis topics oriented to COVID-19 and its associations can be easily carried out during these times. The faculty can discuss amongst themselves and assess the feasibility of topics before deciding to finalize thesis topics.

5. Teleconsultations can be a boon for both patients and medical students. A plethora of cases witnessed through tele-OPDs can be discussed with senior consultants, thereby widening the horizon of their clinical acumen.

6. There should be refresher courses for those who get a degree during this pandemic before they are absorbed in regular jobs.

The above-mentioned problems caused by medical education due to ongoing COVID-19 waves should be effectively mitigated by active participation of medical faculties, health administrators, and medical councils. 


\section{Obstetrics \& Gynecology Science}

Avir Sarkar, et al. COVID-19 pandemic and medical speciality training

\section{Conflict of interest}

No potential conflict of interest relevant to this article was reported.

\section{Ethical approval}

This study does not require approval of the Institutional Review Board because no patient data is contained in this article. The study was performed in accordance with the principles of the Declaration of Helsinki.

\section{Patient consent}

Written informed consent and the use of images from patients are not required for the publication.

\section{Funding information}

None.

\section{References}

1. WHO. WHO Coronavirus (COVID-19) Dashboard [Internet]. Genève (IN): CH; c2021 [updated 2021 August 13]. Available from: https://covid19.who.int/.

2. The Lancet. India's COVID-19 emergency. Lancet 2021;397:1683.

3. Lucey $C R$, Johnston SC. The transformational effects of COVID-19 on medical education. JAMA 2020;324:1033-4.

4. Indianexpress. Centre deploys final-year MBBS students as Covid warriors [Internet]. Noida (IN): Indianexpress; c2021 [updated 2021 May 3]. Available from: https:// indianexpress.com/article/india/after-devi-shettyproposal-centre-deploys-mbbs-students-as-covid-warriors-7300416/.

5. Sarkar A, Saha PK, Arora A. COVID-19 pandemic and infertility: gynecological dilemma from an Indian perspective. Reprod Sci 2021;28:1020-2.

6. Akers A, Blough C, lyer MS. COVID-19 implications on clinical clerkships and the residency application process for medical students. Cureus 2020;12:e7800. 